\title{
Surfactant and Pulmonary Blood Flow Distributions following Treatment of Premature Lambs with Natural Surfactant
}

\author{
Alan Jobe, Machiko Ikegami, Harris Jacobs, \\ and Sally Jones \\ Department of Pediatrics, Harbor-University of California, Los \\ Angeles Medical Center, University of California, Los Angeles \\ School of Medicine, Torrance, California 90509
}

bstract. Prematurely delivered lambs were treated with radiolabeled natural surfactant by either tracheal instillation at birth and before the onset of mechanical ventilation, or after $23 \pm 1( \pm S E)$ min of mechanical ventilation. Right ventricular blood flow distributions, left ventricular outputs, and left-to-right ductal shunts were measured with radiolabeled microspheres. After sacrifice, the lungs of lambs receiving surfactant at birth inflated uniformly with constant distending pressure while the lungs of lambs treated after a period of ventilation had aerated, partially aerated, and atelectatic areas. All lungs were divided into pieces which were weighed and catalogued as to location. The amount of radiolabeled surfactant and microsphere-associated radioactivity in each piece of lung was quantified. Surfactant was relatively homogenously distributed to pieces of lung from lambs that were treated with surfactant at birth; $48 \%$ of lung pieces received amounts of surfactant within $\pm 25 \%$ of the mean value. Surfactant was preferentially recovered from the aerated pieces of lungs of lambs treated after a period of mechanical ventilation, and the distribution of surfactant to these lungs was very nonhomogeneous. Right ventricular blood flow distributions to the lungs were quite homogeneous in both groups of lambs. However, in 8 of 12 lambs, pulmonary blood flow was preferentially directed away from those pieces of lung that received relatively large amounts of surfactant and toward pieces of lung that received less surfactant. This acute redirection of pulmonary blood flow distribution may result from

Address all correspondence to Dr. Jobe.

Received for publication 8 February 1983 and in revised form 4 October 1983.

J. Clin. Invest.

(c) The American Society for Clinical Investigation, Inc.

0021-9738/84/03/0848/09 $\$ 1.00$

Volume 73, March 1984, 848-856 the local changes in compliances within the lung following surfactant instillation.

\section{Introduction}

The intratracheal administration of a variety of surfactant preparations to prematurely delivered animals and infants with respiratory distress syndrome (RDS) ${ }^{1}$ has improved pulmonary function. In most studies, surfactant treatments were administered by injecting suspensions of surfactant into the fluid-filled airways of animals at birth and before the initiation of breathing (1-3). A surfactant suspension also can be administered to previously ventilated animals by tracheal instillation $(4,5)$. While the tracheal instillation of surfactant after a period of ventilation may lead to a clinical response of shorter duration than a treatment given at birth (4), such an approach has been used for most of the clinical trials (6-8). After surfactant instillation, both premature animals and infants with RDS have prompt improvements in $\mathrm{PaO}_{2}$ values, compliance, and a temporary clearing of the chest $x$-ray (1-8). Surfactant when administered to both prematurely delivered and adult animals can be found by histologic techniques in the alveoli $(9,10)$. However, if surfactant suspensions distribute to the lung as do particles administered by either aerosol or by tracheal instillation, a nonhomogeneous distribution should occur (11). Such a distribution of a substance that will acutely change the degree of alveolar aeration and lung compliance may secondarily affect the distribution of pulmonary blood flow. Thus, we measured the distribution of both natural surfactant and pulmonary blood flow following surfactant instillations given to premature lambs either at birth and before breathing, or after the initiation of ventilation.

\section{Methods}

Delivery and instrumentation of lambs. After premedication of datemated pregnant ewes with ketamine and atropine and spinal anesthesia,

1. Abbreviation used in this paper: RDS, respiratory distress syndrome. 
16 lambs at 120 -d gestational age (term $=150 \mathrm{~d}$ ) were delivered by hysterotomy as previously described $(4,5)$. In brief, the fetal neck was exposed through a small uterine incision and an endotracheal tube was secured by tracheotomy. Approximately $10 \mathrm{ml}$ of fetal lung fluid was removed through the endotracheal tube. Following sampling of cord venous blood, the lambs were delivered, dried, and ventilated with $100 \%$ oxygen by hand for $\sim 30 \mathrm{~s}$ with an anesthesia bag by using a peak inspiratory pressure of $30 \mathrm{~cm} \mathrm{H}_{2} \mathrm{O}$ and a rate of 40 breaths/min. Then, the lambs were ventilated with Sechrist IV-100 pressure-limited infant ventilators (Sechrist Industries, Inc., Anaheim, CA) with $100 \%$ humidified oxygen. Ventilator settings were an initial peak inspiratory pressure of $28 \mathrm{~cm} \mathrm{H}_{2} \mathrm{O}$, a positive end expiratory pressure of $2 \mathrm{~cm} \mathrm{H}_{2} \mathrm{O}$, a rate of $30 \mathrm{breaths} / \mathrm{min}$, and an inspiratory time of $1 \mathrm{~s}$. Subsequently, only peak inspiratory pressures were changed in an attempt to normalize $\mathrm{PCO}_{2}$ values. A 5-Fr catheter was placed in the distal aorta via an umbilical artery for continuous recording of blood pressure, heart rate, and sampling of blood for blood-gas measurements. Soon after birth and following infiltration of the superficial tissues of the neck with local anesthesia, a 3.5-Fr infant-feeding tube was passed into the right ventricle via the right external jugular vein. A second 3.5-Fr catheter was passed into the left ventricle via the right carotid artery. Catheter positions were confirmed by the contour of the pressure tracings. All lambs were paralyzed with $0.1 \mathrm{mg} / \mathrm{kg}$ pancuronium bromide (Pavulon, Organon Teknika Corp., Aurora, CO). Body temperature was maintained with radiant warmers and supplemental heat lamps. The lambs received a continuous infusion of $100 \mathrm{ml} / \mathrm{kg}$ per $24 \mathrm{~h}$ of $10 \%$ dextrose in water via the arterial catheter. Expiratory tidal volumes and lung compliance values were measured and reported as before (4). The lambs were sacrificed by a cisternal injection of lidocaine and exsanguination.

Surfactant treatments. Each lamb was treated with a surfactant suspension in $0.45 \%$ saline that contained $100 \mathrm{mg}$ natural surfactant lipid, which was a mixture of natural sheep surfactant isolated following alveolar lavage of adult sheep lungs and a trace amount of $\left[{ }^{3} \mathrm{H}\right]$ palmitic acidlabeled natural sheep surfactant. The labeled surfactant was isolated from lavage fluid from young lambs $\sim \mathbf{4 0} \mathrm{h}$ after an intravascular injection of $15 \mathrm{mCi}\left[{ }^{3} \mathrm{H}\right]$ palmitic acid (New England Nuclear, Boston, MA) (11). Greater than $65 \%$ of the lipid soluble radioactivity in this naturally labeled surfactant was associated with phosphatidylcholine. The labeled natural surfactant contained $0.6 \mu \mathrm{Ci}{ }^{3} \mathrm{H}$-labeled phosphatidylcholine. The surfactant suspension also contained $0.3 \mu \mathrm{Ci}\left[{ }^{14} \mathrm{C}\right]$ dipalmitoylphosphatidylcholine $(100 \mathrm{Ci} / \mathrm{mol}$ ) (New England Nuclear), which had been sonicated into suspension before addition to the natural surfactant (13). The composition, surface properties, and effects on lung function after the instillation of this natural surfactant have been reported (4).

For the six lambs treated at birth, a $3.9 \mathrm{ml}$ surfactant suspension was mixed with the fetal lung fluid by syringe while the lamb was still inside the uterus and before the initiation of ventilation. No attempt was made to uniformly orient these lambs within the uterus. The lambs were then delivered and ventilated with a hand bag while being rotated in an effort to optimize the distribution of the surfactant. The other 10 lambs were ventilated sternum down for $23 \pm 1 \mathrm{~min}$. Then, they were disconnected from the ventilators, and the same surfactant suspension which was diluted to $15 \mathrm{ml}$ was instilled over $15 \mathrm{~s}$ as the lambs were rotated $(4,5)$. The lambs were reconnected to the ventilators and were rotated for a further $30 \mathrm{~s}$ to optimize distribution of the surfactant suspension within the airways. The lambs were returned to a sternumdown, midline position for the duration of the experiment. This treatment procedure is similar to that used for the treatment of infants with RDS (6-8).
Radiolabeled microsphere injections. The distribution of blood flow to the lungs, the left-to-right shunt through the ductus arteriosus, and cardiac outputs were measured by using radiolabeled microspheres (14). $15 \pm 2 \mu \mathrm{m}($ mean $\pm \mathrm{SD})$ diameter microspheres (New England Nuclear) labeled with ${ }^{57} \mathrm{Co},{ }^{46} \mathrm{Sc}$, or ${ }^{113} \mathrm{Sn}$ were injected sequentially into the lambs treated with surfactant at birth. The first microsphere injection was into the right ventricle of four of six lambs at $13 \pm 1 \mathrm{~min}$ of age, the second injection was into the left ventricle of five of six lambs at $22 \pm 1 \mathrm{~min}$ of age, and the third injection was into the right ventricle of all six lambs at $23 \pm 2 \mathrm{~min}$ of age. For six of the lambs treated with surfactant at 23 min of age, microspheres were injected into the right ventricle at $21 \pm 1$ and $44 \pm 3 \mathrm{~min}$ of age, and into the left ventricle in four of six lambs at $42 \pm 3 \mathrm{~min}$ of age. The other four lambs did not receive microspheres because the lungs were used for dry-to-wet weight ratio measurements. Starting just before the left ventricular injections, reference samples were withdrawn with a Harvard pump from the aortic and right ventricular catheters at a rate of $6 \mathrm{ml} / \mathrm{min}$ for $2 \mathrm{~min}$ into heparinized glass syringes (14). The blood volume of each reference sample immediately was divided into three scintillation vials and sequential rinses of the syringes were added to the vials. After sacrifice, the lungs were removed and divided into multiple pieces (see below) and the rest of the body was carbonized. Left-to-right ductal shunt expressed as percentage of left ventricular output directed to the lungs was calculated as the sum of radioactivity in the pieces of lung from microspheres injected into the left ventricle divided by the total radioactivity injected into the left ventricle. Cardiac output was calculated from the single reference sample drawn from the distal aorta. We have not detected right-to-left ductal shunts in this animal preparation $(15,16)$. The average number of microspheres resulting from the right ventricular injections trapped in each piece of lung was $>3,800$ microspheres/piece, and the shunt fraction from the left-to-right ductal shunt resulted in $>1,000$ spheres/piece of lung. The radioactivity of the isotopes was determined simultaneously, and crosschannel contamination was corrected by computer by using the appropriate pure isotope standards.

Processing of lungs. After sacrifice, the lungs were removed intact from the animals while still attached to the endotracheal tube. The lungs of the lambs treated at birth and sacrificed at $24 \pm 1 \mathrm{~min}$ of age were inflated to $30 \mathrm{~cm} \mathrm{H}_{2} \mathrm{O}$ pressure for $30 \mathrm{~s}$. The pressure then was decreased to $15 \mathrm{~cm} \mathrm{H}_{2} \mathrm{O}$ and the lobes were separated by placing small pieces of aluminum foil in the fissures. The lungs of these six lambs inflated uniformly. The lungs were frozen by immersion in liquid nitrogen while maintaining inflation to $15 \mathrm{~cm} \mathrm{H}_{2} \mathrm{O}$ pressure and stored at $-20^{\circ} \mathrm{C}$. While frozen, the upper lobes were cut from the lungs with a band saw and divided into pieces. The left and right lower lobes were cut into vertical slices, and then into pieces of $\sim 1 \mathrm{~cm}^{3}$. The location of each piece within the lung was recorded and each piece was weighed. The mean weight of the six lungs was $83 \pm 6 \mathrm{~g}$ and the mean number of pieces resulting from each lung was $101 \pm 9$ pieces.

The lungs of six of the lambs treated with surfactant at $23 \mathrm{~min}$ of age and sacrificed at $46 \pm 3 \mathrm{~min}$ of age following microsphere injections had an average weight of $78 \pm 8 \mathrm{~g}$. The lungs were similarly inflated with $30 \mathrm{~cm} \mathrm{H}_{2} \mathrm{O}$ pressure and then, held at $15 \mathrm{~cm} \mathrm{H}_{2} \mathrm{O}$ distending pressure. However, the lungs did not inflate uniformly. Large areas were atelectatic and other areas of the lungs appeared either partially or fully inflated. Therefore, these three different appearing areas of lung were outlined with a vital stain. The lungs were divided into $51 \pm 4$ approximately equal-sized pieces, and each piece was categorized as atelectatic, partially aerated, or fully aerated. The lobar location and weight of each piece were recorded. 
The microsphere-associated radioactivity was determined for all pieces and then, each piece of lung was homogenized with an Ultra-turax homogenizer (Tekmar Co., Cincinnati, $\mathrm{OH}$ ) in water such that the homogenate contained $20 \%$ tissue (wt/vol). An aliquot of each homogenate was extracted with a 2:1 mixture of chloroform:methanol (17).

The lungs of four lambs treated with surfactant after ventilation similarly were removed and inflated. One lung did not have clearly distinguishable aerated and atelectatic volumes, and this lung was not processed further. The other three lungs were divided into $45 \pm 1$ pieces weighing $1.7 \pm 0.04 \mathrm{~g}$ based on the degree of aeration as above; approximately one-third of the pieces from each lung were classified as aerated, partially aerated, or atelectatic. The weighed pieces were dried at $70^{\circ} \mathrm{C}$ for $3 \mathrm{~d}$ and reweighed. A dry-to-wet ratio was calculated for each piece.

Phospholipid analysis. Lipid extracts of the homogenates were concentrated under $\mathrm{N}_{2}$ and aliquots of each extract were plated in duplicate on silica gel $\mathrm{H}$ thin layer plates. Phosphatidylcholine was separated from the other lipids by chomatography in one dimension (18), and the phosphatidylcholine was located with iodine vapor. One phosphatidylcholine spot was used for a phosphate assay according to Bartlett (19); the duplicate spot was solubilized in Aquasol II scintillation fluid (New England Nuclear) and the radioactivity quantified. The micromoles of phosphatidylcholine and ${ }^{14} \mathrm{C}$ and ${ }^{3} \mathrm{H}$ radioactivity per gram wet tissue were calculated.

Data analysis and presentation. A mean value per piece of lung for each lamb was obtained for each measurement. All values, then, were divided by the mean value to normalize the numbers. These normalized values are then presented as histograms with interval widths of $10 \%$ about the mean value of 1.0. For example, if all pieces from a lung had the same amount of surfactant per gram lung tissue, then $100 \%$ of the pieces would be in the interval bracketed by $0.95-1.05$ of the mean value (Fig. 1). All pieces having a normalized value $<0.15$ or $>1.85$ times the mean were grouped at the extremes of the distribution intervals.

All values are presented as means $\pm \mathrm{SE}$, unless otherwise indicated. Slopes of curves were calculated by linear regression by the method of least squares, and were tested for significance compared with a slope of 0 by unpaired two-tailed $t$ tests. Differences in the distributions of sur-
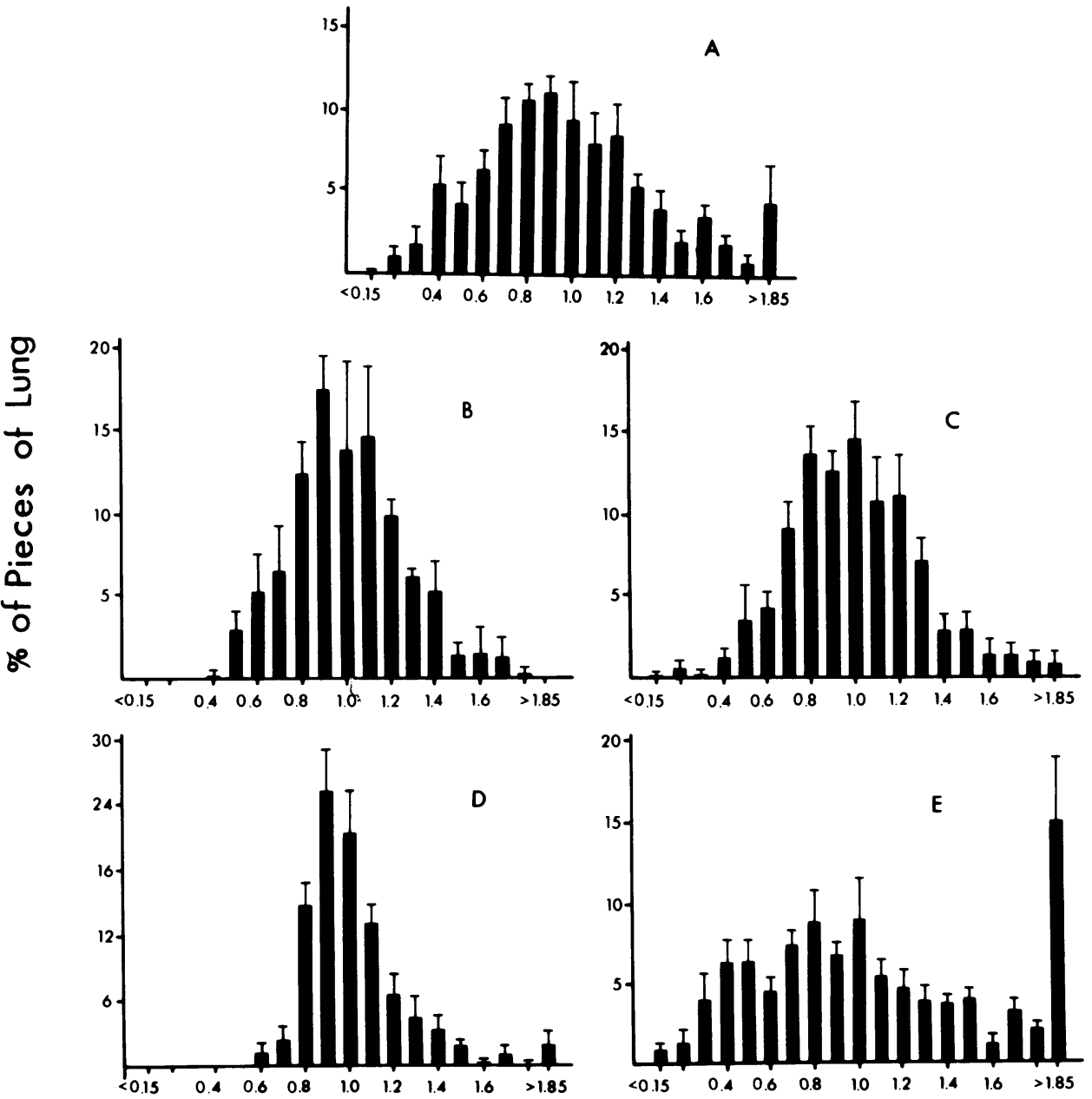

Figure 1. Normalized distributions for six lambs treated with surfactant at birth. All values were calculated as described in Methods and are presented as mean \pm SE percentage of pieces of the lung vs. the $10 \%$ distribution intervals. $(A)$ Distribution of surfactant phosphatidylcholine per gram lung tissue. (B) Distribution of right ventricular output to the lung per gram tissue at $13 \pm 1 \mathrm{~min}$ of age. (C) Distribution of right ventricular output to the lung per gram tissue at $23 \pm 2$ min of age. $(D)$ Distribution of ratios of relative blood flow from the left ventricle via the ductus arteriosus at $22 \pm 1 \mathrm{~min}$ of age to relative blood flow from the right ventricle at $23 \pm 2$ min of age. $(E)$ Distribution of ratios of right ventricular blood flow per gram tissue at $23 \pm 2 \mathrm{~min}$ of age to

\section{DISTRIBUTION INTERVALS} surfactant per gram tissue. 
factant and blood flow to pieces of lung were tested for significance by ANOVA followed by the Student Newman-Keuls multiple comparison procedure.

\section{Results}

Description of lambs. The umbilical vein blood-gas values for these 16 lambs were $\mathrm{pH}, 7.31 \pm 0.02 ; \mathrm{PO}_{2}, 28 \pm 2 \mathrm{mmHg}$; and $\mathrm{PCO}_{2}, 43 \pm 2 \mathrm{mmHg}$. The lambs weighed $1.8 \pm 0.1 \mathrm{~kg}$. The six lambs treated with surfactant at birth and sacrificed at $24 \pm 1$ min of age had aortic blood-gas values of $\mathrm{pH}, 7.39 \pm 0.04 ; \mathrm{PO}_{2}$, $204 \pm 56 \mathrm{mmHg}$; and $\mathrm{PCO}_{2}, 34 \pm 4 \mathrm{mmHg}$ just prior to sacrifice while being supported with $28 \mathrm{~cm} \mathrm{H}_{2} \mathrm{O}$ peak inspiratory pressures. Their expiratory tidal volumes and lung compliance values were $10.9 \mathrm{ml} / \mathrm{kg}$ and $0.42 \pm 0.03 \mathrm{ml} / \mathrm{cm} \mathrm{H}_{2} \mathrm{O}$ per kg, respectively. The mean blood-gas values for the other 10 lambs were $\mathrm{pH}$, $7.05 \pm 0.04 ; \mathrm{PO}_{2}, 66 \pm 18 \mathrm{mmHg}$; and $\mathrm{PCO}_{2}, 81 \pm 6 \mathrm{mmHg}$ at 20 min of age just prior to surfactant instillation. At that time, expiratory tidal volume was only $2.6 \pm 0.9 \mathrm{ml} / \mathrm{kg}$ and lung compliance was $0.09 \pm 0.01 \mathrm{ml} / \mathrm{cm} \mathrm{H}_{2} \mathrm{O}$ per $\mathrm{kg}$. The lambs responded to the surfactant with blood-gas values at sacrifice $23 \mathrm{~min}$ after treatment of $\mathrm{pH}, 7.23 \pm 0.03 ; \mathrm{PO}_{2}, 161 \pm 32 \mathrm{mmHg}$; and $\mathrm{PCO}_{2}$, $44 \pm 3 \mathrm{mmHg}$ while the lambs were being ventilated with $32 \pm 1$ $\mathrm{cm} \mathrm{H}_{2} \mathrm{O}$ peak inspiratory pressures. Mean tidal volume increased to $7.0 \pm 0.7 \mathrm{ml} / \mathrm{kg}$ and compliance increased to a value of $0.24 \pm 0.02 \mathrm{ml} / \mathrm{cm} \mathrm{H}_{2} \mathrm{O}$ per $\mathrm{kg}$. Cardiac outputs were measured for six lambs and were $208 \pm 28 \mathrm{~cm}^{3} / \mathrm{kg}$ per min. The left-toright ductal shunt measured in these lambs was $31 \pm 3 \%$ (range, $24-42 \%$ ) of left ventricular output. This shunt value has been corrected for the $4 \pm 1 \%$ of spheres that were not trapped by the systemic capillary bed, as determined by the reference sample drawn from the right ventricle. Less than $4 \%$ of microspheres injected into the right ventricle were detected in the carcass, documenting relatively complete trapping of microspheres by the pulmonary vasculature and no significant right-to-left ductal shunt.

Dry-to-wet weight ratios. The dry-to-wet weight ratios were calculated for the differentially aerated pieces of lung from three lambs following treatment with surfactant after a period of ventilation. The mean \pm SD values were: aerated, $0.0854 \pm 0.0106$; partially aerated, $0.0872 \pm 0.0154$; and atelectatic, $0.0946 \pm 0.0070$. The ratios for aerated and partially aerated pieces of lung were not different; however, there was less water in the atelectatic pieces than in either of the other two groups $(P>0.01)$. The absolute differences were very small and subsequent data are expressed per gram wet weight without a correction for the $\sim 1 \%$ difference in lung water between atelectatic and aerated or partially aerated pieces.

Distribution of surfactant. The lungs of lambs treated at birth with surfactant were not atelectatic when inflated after sacrifice, and the surfactant was distributed relatively homogenously throughout the pieces of lung tissue (Fig. $1 A$ ). $48 \%$ of the pieces contained an amount of surfactant that was within $\pm 25 \%$ of the mean, and few pieces contained either very little or large amounts of surfactant. For each lamb, the distribution of surfactant to different lobes of the lung was not uniform; however, mean values of surfactant per gram indicate no preferential lobar distribution of surfactant after treatment at birth (Table I).

In contrast, the lungs of the lambs that were treated after a period of ventilation did not inflate uniformly. Large contiguous volumes of lung were only partially aerated or entirely

Table I. Relative Distribution of Surfactant and Blood Flow's by Lobes

\begin{tabular}{|c|c|c|c|c|c|c|c|c|c|}
\hline & $\begin{array}{l}\text { Left upper } \\
\text { lobe }\end{array}$ & $\begin{array}{l}\text { Left middle } \\
\text { lobe }\end{array}$ & $\begin{array}{l}\text { Left lower } \\
\text { lobe }\end{array}$ & $\begin{array}{l}\text { Right upper } \\
\text { lobe }\end{array}$ & $\begin{array}{l}\text { Superior right } \\
\text { middle lobe }\end{array}$ & $\begin{array}{l}\text { Inferior right } \\
\text { middle lobe }\end{array}$ & $\begin{array}{l}\text { Right lower } \\
\text { lobe }\end{array}$ & $\begin{array}{l}\text { Total left } \\
\text { lung }\end{array}$ & $\begin{array}{l}\text { Total right } \\
\text { lung }\end{array}$ \\
\hline $\begin{array}{l}\text { Lambs treated } \\
\text { at birth, NS* } \\
\text { per gram } \\
\text { lung }\end{array}$ & $\begin{array}{r}0.83 \\
\pm 0.50\end{array}$ & $\begin{array}{r}1.07 \\
\pm 0.51\end{array}$ & $\begin{array}{r}0.95 \\
\pm 0.42\end{array}$ & $\begin{array}{r}1.08 \\
\pm 0.47\end{array}$ & $\begin{array}{r}1.05 \\
\pm 0.43\end{array}$ & $\begin{array}{r}0.98 \\
\pm 0.33\end{array}$ & $\begin{array}{r}1.05 \\
\pm 0.37\end{array}$ & $\begin{array}{r}0.98 \\
\pm 0.45\end{array}$ & $\begin{array}{r}1.02 \\
\pm 0.40\end{array}$ \\
\hline $\begin{array}{l}\text { Lambs treated } \\
\text { after } \\
\text { ventilation. } \\
\text { NS per gram } \\
\text { lung }\end{array}$ & $\begin{aligned} & 1.61 \S \\
\pm & 0.88\end{aligned}$ & $\begin{aligned} & 1.94 \S \\
\pm & 0.75\end{aligned}$ & $\begin{array}{r}1.04 \\
\pm 0.75\end{array}$ & $\begin{array}{c}1.03 \S \\
\pm 0.88\end{array}$ & $\begin{array}{c}1.02 \S \\
\pm 0.94\end{array}$ & $\begin{array}{c}1.92 \S \\
\pm 0.57\end{array}$ & $\begin{array}{r}0.58 \\
\pm 0.41\end{array}$ & $\begin{array}{c}1.26 \ddagger \\
\pm 0.84\end{array}$ & $\begin{array}{r}0.77 \\
\pm 0.65\end{array}$ \\
\hline $\begin{array}{l}\mathrm{RV}^{*} \text { blood flow } \\
\text { in lung } \\
\text { before NS } \\
\text { treatment }\end{array}$ & $\begin{array}{r}0.95 \\
\pm 0.16\end{array}$ & $\begin{array}{r}0.93 \\
\pm 0.17\end{array}$ & $\begin{array}{r}1.06 \\
\pm 0.21\end{array}$ & $\begin{array}{r}0.94 \\
\pm 0.56\end{array}$ & $\begin{array}{r}0.79 \\
\pm 0.19\end{array}$ & $\begin{array}{r}0.96 \\
\pm 0.19\end{array}$ & $\begin{array}{r}1.07 \\
\pm 0.21\end{array}$ & $\begin{array}{r}1.03 \\
\pm 0.21\end{array}$ & $\begin{array}{r}0.98 \\
\pm 0.31\end{array}$ \\
\hline
\end{tabular}

Values are given as mean \pm SD. * NS, natural surfactant; RV, right ventricle. $\ddagger$ Total left lung $>$ total right lung $(P<0.01)$. $\S$ Upper lobes $>$ lower lobes $(P<0.05)$. 
atelectatic to visual inspection. Sequentially, more surfactant was found in aerated than partially aerated pieces of lungs, and more was found in partially aerated than in atelectatic pieces of lung (Table II). The aerated pieces of lung contained 5.4 times more surfactant per gram than atelectatic pieces and 2.5 times more surfactant per gram than partially aerated pieces. Thus, visual inspection of the lungs held at $15 \mathrm{~cm} \mathrm{H}_{2} \mathrm{O}$ static airway pressure accurately identified the location and distribution of the surfactant in lambs treated with surfactant after a period of ventilation. The pieces of lung for these lambs distributed such that only $24 \%$ of pieces received amounts of surfactant per gram tissue within $\pm 25 \%$ of the mean (Fig. $2 A$ ). On the average, more surfactant was found in pieces from the left than right lungs $(P<0.01)$, and the upper lobes of each lung received
Table II. Relative Amount of ${ }^{3} \mathrm{H}$-labeled Natural Surfactant per Gram Tissue (No. of pieces assayed)

\begin{tabular}{clll}
\hline & Aerated & Partially aerated & Atelectatic \\
\hline Lamb & & & \\
1 & $1.83 \pm 0.16(22)$ & $0.92 \pm 0.11(19)$ & $0.31 \pm 0.04(24)$ \\
2 & $1.66 \pm 0.18(25)$ & $0.54 \pm 0.06(16)$ & $0.43 \pm 0.06(15)$ \\
3 & $1.77 \pm 0.13(19)$ & $0.64 \pm 0.06(22)$ & $0.17 \pm 0.03(8)$ \\
4 & $1.09 \pm 0.09(33)$ & $0.38 \pm 0.07(5)$ & - \\
5 & $2.16 \pm 0.16(14)$ & $0.87 \pm 0.09(24)$ & $0.34 \pm 0.03(19)$ \\
6 & $2.14 \pm 0.17(8)$ & $0.92 \pm 0.08(17)$ & $0.38 \pm 0.05(18)$ \\
Average & 1.78 & 0.71 & 0.33 \\
& & & \\
\hline
\end{tabular}
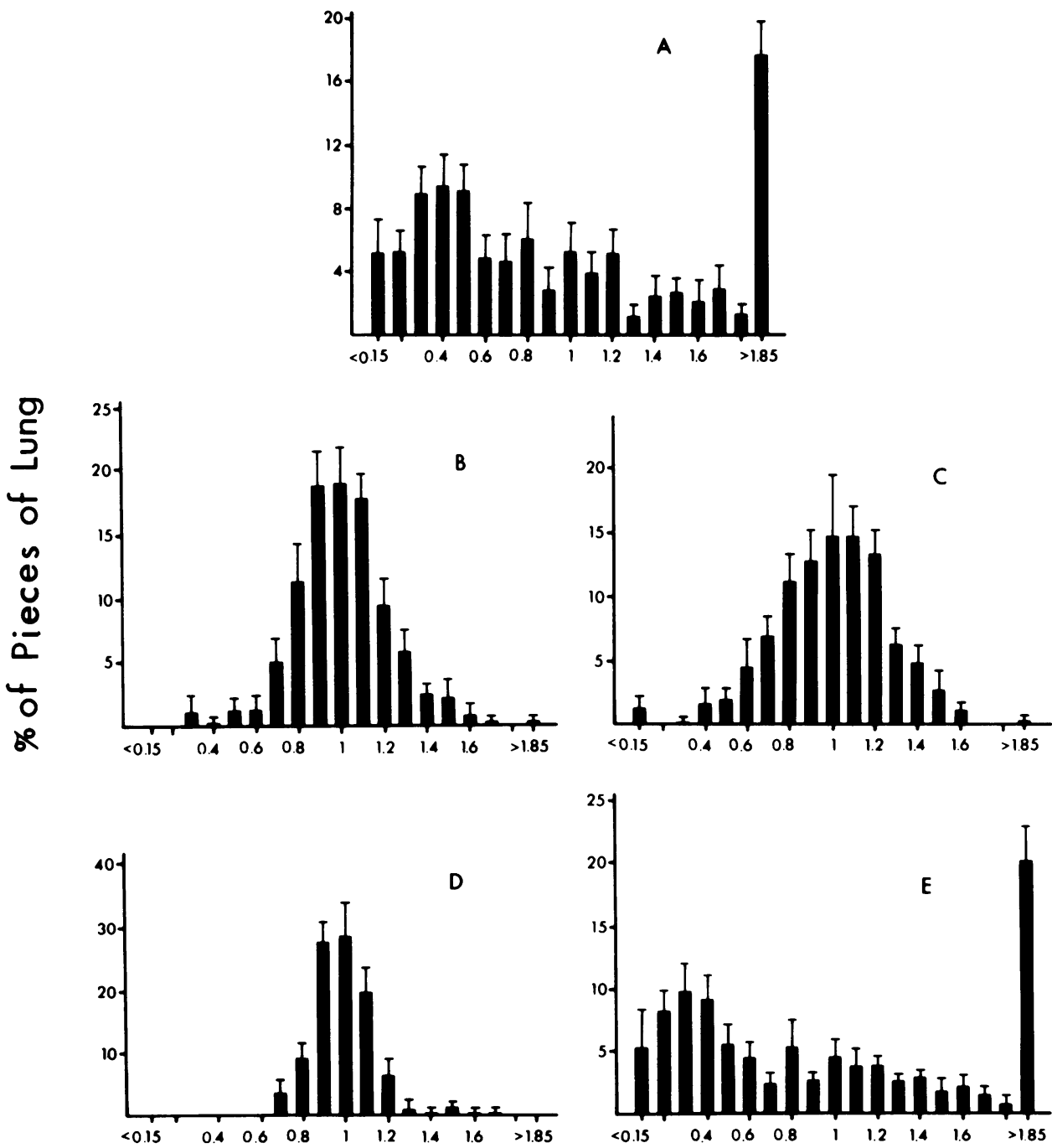

DISTRIBUTION INTERVALS
Figure 2. Normalized distributions for six lambs treated with surfactant at $23 \pm 1 \mathrm{~min}$ of age. All values were calculated as described in Methods and are presented as mean \pm SE percentage of pieces of the lungs vs. the $10 \%$ distribution intervals. $(A)$ Distribution of surfactant phosphatidylcholine per gram lung tissue. $(B)$ Distribution of right ventricular output to the lung per gram tissue at $21 \pm 1$ min of age. $(C)$ Distribution of right ventricular output to the lung per gram tissue at $44 \pm 3 \mathrm{~min}$ of age. $(D)$ Distribution of ratios of relative blood flow from the left ventricle via the ductus arteriosus at $42 \pm 3 \mathrm{~min}$ of age to relative blood flow from the right ventricle at $44 \pm 3$ min of age. $(E)$ Distribution of ratios of right ventricular blood flow per gram tissue at $44 \pm 3 \mathrm{~min}$ of age to surfactant per gram tissue. 
more surfactant than the lower lobes (Table I). The synthetic dipalmitoylphosphatidylcholine was distributed to the lungs of both groups of lambs in the same pattern as was the natural surfactant (data not shown).

Distribution of pulmonary blood flow. Radiolabeled microspheres were injected into the right ventricle to measure the distribution of blood flow to the lungs. In lambs treated with surfactant at birth, the pulmonary blood flow at 13 and $23 \mathrm{~min}$ of age was relatively homogenous to the pieces of lung. At the early and late injection times, 69 and $63 \%$ of the pieces received blood flows within $\pm 25 \%$ of the mean (Fig. $1 B$ and $C$ ). In the five lambs receiving injections of microspheres into the left ventricle, the distribution of the normalized shunt flow from the aorta via the patent ductus arteriosus to the lungs had the same distribution as the blood flow from the right ventricle (Fig. 1 $D$ ). The results indicated very good mixing of blood from the two ventricles.

Pulmonary blood flow distribution was measured in lambs treated with surfactant after a period of ventilation by injecting microspheres immediately before and $22 \pm 2$ min after surfactant treatment. The histograms of normalized blood flow per gram tissue before surfactant treatment indicated a relatively homogenous distribution of blood flow throughout the lung with $77 \%$ of the pieces receiving flows within $\pm 25 \%$ of the mean (Fig. $2 \mathrm{~B}$ ). There was no consistent pattern of preferential blood flow from the right ventricle to different lobes of the lung per gram tissue (Table I). After surfactant therapy, the overall distribution of flow was somewhat less homogenous with $67 \%$ of the pieces receiving flows within $\pm 25 \%$ of the mean flow (Fig. $2 C$ ). The histogram of the ratios of normalized blood flow from the right ventricle and from the left-to-right ductal shunt in these lambs documented good mixing of the pulmonary blood flow from the two sources (Fig. 2 D).

Matching of surfactant and blood flow distributions. In lambs treated with surfactant at birth, the normalized distribution of the ratio of surfactant per gram lung to blood flow per gram lung resulted in a more dispersed distribution than was the distribution of surfactant per gram lung. Only $35 \%$ of pieces of lung received within $\pm 25 \%$ of the mean value (Fig. $1 E$ ). $15 \pm 4 \%$ of the pieces of lung from the six lambs had a ratio of surfactant to blood flow of $>1.85$. This dispersion of the distribution histogram indicated that blood flow distribution did not match surfactant distribution. The correlation of surfactant distribution with blood flow for the 133 pieces of lung from a single lamb indicated a significant negative effect of the presence of surfactant on the distribution of pulmonary blood flow (Fig. 3). The decrease in perfusion to pieces of lung receiving relatively large amounts of surfactant was detected by linear regression analysis in four of six lambs $(P<0.01)$. No correlation between distributions of perfusion and surfactant was detected in the other two lambs.

An effect of surfactant distribution on pulmonary blood flow distribution also was detected in the lambs treated with surfactant after a period of ventilation. The ratio of surfactant

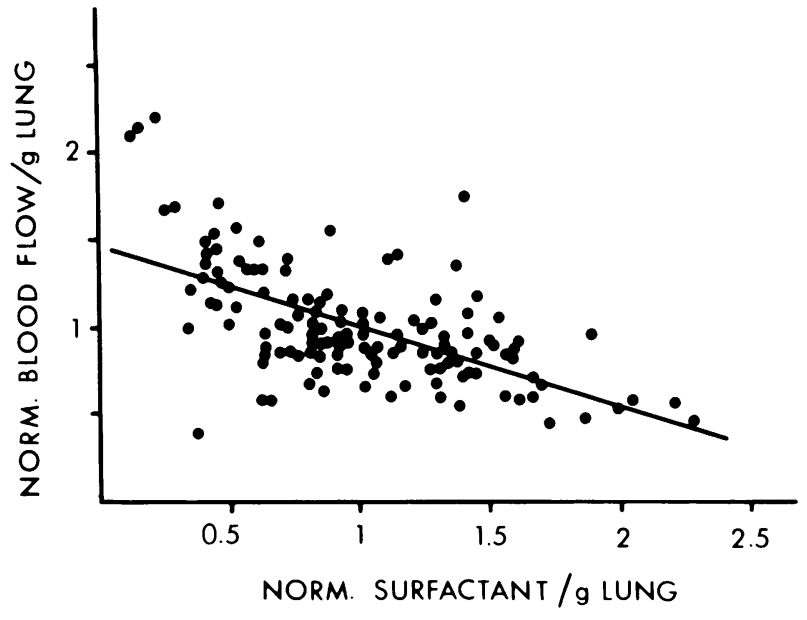

Figure 3. Correlation of normalized (norm.) values of right ventricular blood flow per gram tissue with surfactant per gram tissue for the 133 pieces of lung from a lamb. The slope of the regression line fit by the method of least squares is significantly different from zero $(P$ $<10^{-5}$ ).

distribution to blood flow distribution was bimodel (Fig. $2 E$ ) and similar to that of the histogram for the surfactant distribution alone (Fig. $2 A$ ). The effect of surfactant on pulmonary blood flow distributions was tested in these six lambs by comparing by linear regression analysis changes in blood flow distributions before and after surfactant treatments. In four of six lambs, there was a significant negative correlation between surfactant per gram tissue and pulmonary blood flow per gram tissue $(P<0.04)$. The presence of surfactant in the tissue resulted in a relative fall in blood flow to those pieces of lung and an increase in relative blood flow to pieces of lung that received very little of the exogenously administered surfactant (Fig. 4). In two of six lambs, pulmonary blood flow distribution did not change significantly.

\section{Discussion}

We treated lambs with surfactant at birth and before the initiation of ventilation because most experimental demonstrations of the efficacy of surfactant administrations have involved treatment of prematurely delivered animals before the onset of ventilation $(1-4,20,21)$. Surfactant treatments of premature rabbit lungs improve lung compliance with a "dose-response curve" that demonstrates no further improvements in compliance measurements at doses of surfactant $>1.1 \mathrm{mg}$ surfactant lipid/g lung (22). The compliance changes were insensitive to the volume used to instill the surfactant. Lungs of premature rabbits and lambs treated with surfactant at birth were generally well aerated visually; however, patchy atelectatic areas were described and confirmed microscopically $(1,9)$. This patchy atelectasis could 


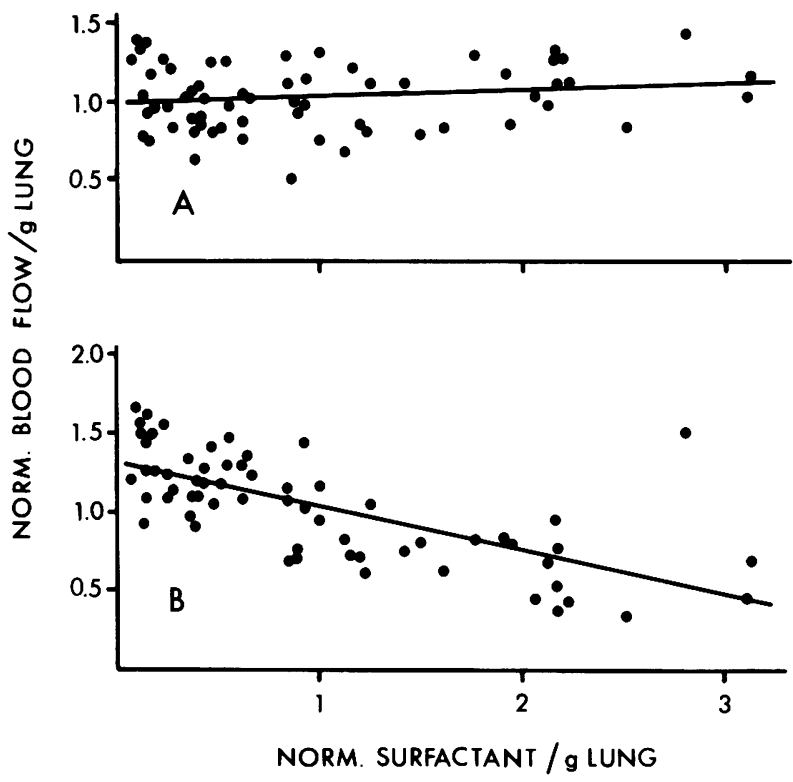

Figure 4. Correlations of normalized (norm.) values for right ventricular blood flow per gram tissue $(A)$ before and $(B)$ after surfactant instillation with surfactant per gram tissue for the 64 pieces from one lamb. $(A)$ The slope of the regression line is not different from zero. $(B)$ The slope of the regression line is significantly different from zero $\left(P<10^{-5}\right)$.

represent volumes of lung not receiving the exogenously administered surfactant; however, such atelectasis also is characteristic of the lungs of the term newborn in the early hours of life. The assumption has been that the normal physiologic clearance of fetal lung fluid after birth via the distal airways and alveoli primarily to the vascular space (23) will result in the exogenously administered surfactant being well-distributed throughout the lung. The surfactant was relatively homogenously distributed throughout the uniformly inflated lungs of lambs treated with surfactant at birth. However, this technique of surfactant administration is not easily adapted to clinical practice.

In all clinical studies to date, surfactant has been administered from shortly after the onset of breathing to up to $33 \mathrm{~h}$ after ventilatory support $(6,7,24)$. Except for the use of dry surfactant (24), the infants were treated by tracheal injection with a suspension of surfactant in a volume of $\sim 3.5-7 \mathrm{ml} / \mathrm{kg}$ containing $\sim 50-125 \mathrm{mg}$ surfactant lipid/ $\mathrm{kg}(6,7)$. The dose was based on a dose-response curve for the treatment of prematurely delivered lambs with natural sheep surfactant (25). The volume of the suspension has been an empiric compromise designed to optimize surfactant distribution while minimizing potential problems resulting from flooding the airways. While the efficacy of varying volumes of the suspension has not been studied systematically, $7 \mathrm{ml} / \mathrm{kg}$ surfactant suspensions do not significantly change gas exchange or cardiovascular status in premature lambs (26). Thus, we chose a dose and volume of surfactant suspension consistent with previous clinical and experimental usage. Surfactant was localized to alveoli following administration to fetal or adult animals; however, the distribution seemed to be nonuniform $(1,9)$. Radiolabeled particles given to rats and hamsters by instillation in $1.5 \mathrm{ml} / \mathrm{kg}$ suspensions were nonuniformly distributed with preferential deposition to dependent lung locations, while aerosolized particles were more evenly distributed with preferential deposition to the apical lobes (11).

We found more surfactant in the left rather than right lungs and in upper vs. lower lobes of the lungs of lambs treated after a period of ventilation. Since these lungs were cut in pieces based on a visual assessment of degree of inflation at a static pressure of $15 \mathrm{~cm} \mathrm{H}_{2} \mathrm{O}$, the distribution of surfactant was not strictly comparable with that measured in the lungs of lambs treated at birth with surfactant. However, the atelectatic vs. aerated areas had predominantly lobar distributions and were large compared with the size of pieces of lung actually sampled $\left(\sim 1 \mathrm{~cm}^{3}\right)$. Thus, random sampling of pieces of lung would not have changed the overall distribution pattern very much. While all pieces of lung received some surfactant, the pieces of lung that were aerated after static inflation contained relatively large amounts of surfactant, and atelectatic pieces received much less surfactant. In contrast, the lungs of lambs treated at birth were uniformly inflated despite some pieces of lung receiving relatively little surfactant. For example, $\sim 10 \%$ of the aerated pieces of lung of lambs treated at birth contained amounts of surfactant per gram that did not result in inflation in lambs treated after ventilation. More than $40 \%$ of the aerated pieces from lungs of lambs treated at birth contained amounts of surfactant per gram lung that resulted in only partial aeration in the previously ventilated lambs. Possibly following ventilation, larger amounts of surfactant are needed per gram lung to achieve aeration because of bronchiolar epithelial damage and the resultant pulmonary edema that occurs with ventilation of the surfactantdeficient lung $(20,21)$. Such damage may result in the entrance into the airway of proteins that interfere with the surface tensionlowering properties of surfactant (12). Thus, it is likely that one must accept a less effective and relatively nonhomogeneous distribution of surfactant to the immature lung following airway instillation after the initiation of ventilation.

We measured relative pulmonary blood flow by measuring the trapping of radiolabeled microspheres by the pulmonary microvasculature (27). In adult animals, such measurements are made following central venous rather than right ventricular injections to ensure complete mixing of the blood and microspheres. While we have not detected large right-to-left shunts through the foramen ovale in similarly studied lambs $(15,16)$, we injected the microspheres into the right ventricle to avoid such shunts. The completeness of mixing can be assessed only indirectly in this model. Very few pieces of lung received large numbers or small numbers of microspheres, and the relative number of microspheres within a piece of lung with consecutive injections was similar. These results indicate good mixing. A large or variable ductal shunt also could perturb the distribution 
data if that shunt flow did not mix well with the pulmonary artery blood flow. While the lambs had large left-to-right ductal shunts that accounted for $24-42 \%$ of the left ventricular output, this shunted blood was distributed equivalently to both lungs, implying good mixing.

Surfactant treatment after a period of ventilation resulted in a prompt increase in $\mathrm{PO}_{2}$ to mean values over $200 \mathrm{~mm} \mathrm{Hg}$, and a mean $\mathrm{PO}_{2}$ of $161 \mathrm{mmHg}$ at sacrifice. The percent functional right-to-left pulmonary shunt can thus be assumed to be $\sim 40 \%$ of the cardiac output (28). We hypothesized that pulmonary blood flow would be directed toward regions of lung receiving the most surfactant, and thus, those areas that should be better ventilated. While surfactant distribution and static inflation correlated very well in those lambs treated after a period of ventilation, we do not know which areas of lung actually were ventilated, and thus, where gas exchange actually occurred in the mechanically ventilated lung. The $\mathrm{PO}_{2}$ values suggest that significant gas exchange occurred in regions of lung that appeared aerated and only partially aerated with static inflation because only $39 \%$ of lung pieces were assessed as being aerated, while 33 and $27 \%$ of lung pieces, respectively, were partially aerated or atelectatic. The decrease in blood flow to regions of lung receiving relatively large amounts of surfactant with a relative increase in blood flow to those regions receiving small amounts of surfactant in 8 of 12 lambs might be explained by pressure relationships within the lungs. The nonhomogeneous distribution of surfactant will result in a wide range of compliance changes throughout the lung. In fully aerated areas, the peak inspiratory pressures of $28-31 \mathrm{~cm} \mathrm{H}_{2} \mathrm{O}$ may be transmitted to the pulmonary microvasculature and inhibit blood flow (29). In fact, significant overdistension may occur in areas receiving large amounts of surfactant. In areas of low compliance, there may be very little pressure transmitted from the airways to the pulmonary microvasculature. These maladaptive changes in pulmonary perfusion following surfactant instillation are acute changes and parallel the acute changes noted in the adult dog following segmental atelectasis (30). The chronic effect of surfactant instillation on pulmonary perfusion remains to be studied.

\section{Acknowledgments}

This work was supported by the Department of Health and Human Service Development Grant HD-12714; the Research Career Development Award grant HD-HL 00205 to Dr. Jobe, and the Research Service Award HL-06544 to Dr. Jacobs.

\section{References}

1. Enhorning, G., G. Grossman, and B. Robertson. 1973. Tracheal deposition of surfactant before the first breath. Am. Rev. Respir. Dis. 107:921-926.

2. Enhorning, G., D. Hill, G. Sherwood, E. Cuty, B. Robertson, and C. Bryan. 1978. Improved ventilation of prematurely delivered primates following tracheal deposition of surfactant. Am. J. Obstet. Gynecol. 132:529-536.

3. Adams, F. H., B. Towers, A. B. Osher, M. Ikegami, T. Fujiwara, and M. Nozaki. 1978. Effects of tracheal instillation of natural surfactant in premature lambs. Pediatr. Res. 12:841-848.

4. Jobe, A., M. Ikegami, T. Glatz, Y. Yoshida, E. Diakomanolis, and J. Padbury. 1981. Duration and characteristics of treatment of premature lambs with natural surfactant. J. Clin. Invest. 67:370-375.

5. Jacobs, H., A. Jobe, M. Ikegami, T. Glatz, S. Jones, and L. Barajas. 1982. Premature lambs rescued from respiratory failure with natural surfactant: clinical and biophysical correlate. Pediatr. Res. 16:424-429.

6. Fujiwara, T., S. Chida, Y. Watabe, H. Maeta, T. Morita, and T. Abe. 1980. Artificial surfactant therapy in hyaline-membrane disease. Lancet. I:55-59.

7. Hallman, M., T. A. Merritt, H. Schneider, B. L. Epstein, F. Mannino, D. K. Edwards, and L. Gluck. 1983. Isolation of human surfactant from amniotic fluid and a pilot study of its efficacy in respiratory distress syndrome. Pediatrics. 71:473-482.

8. Smyth, J. A., I. L. Metcalfe, P. Duffty, F. Possmayer, M. H. Bryan, and G. Enhorning. 1983. Hyaline membrane disease treated with bovine surfactant. Pediatrics. 71:913-917.

9. Robertson, B., and G. Enhorning. 1974. The alveolar lining of the premature newborn rabbit after pharyngeal deposition of surfactant. Lab. Invest. 31:54-59.

10. Obladen, M., F. Brendlein, and B. Krempien. 1979. Surfactant substitution. Eur. J. Pediatr. 131:219-228.

11. Brain, J. D., D. E. Knudson, S. P. Sorokin, and M. A. Davis. 1976. Pulmonary distribution of particles given by intratracheal instillation or by aerosol inhalation. Environ. Res. 11:13-33.

12. Ikegami, M., A. Jobe, and T. Glatz. 1981. Surface activity following natural surfactant treatment in premature lambs. J. Appl. Physiol. 51:306-312.

13. Ikegami, M., A. Jobe, H. Jacobs, and S. Jones. 1981. Sequential treatments of premature lambs with an artificial surfactant and natural surfactant. J. Clin. Invest. 68:491-498.

14. Heymann, M. A., B. D. Payne, J. I. E. Hoffman, and A. M. Rudolph. 1977. Blood flow measurements with radionuclide-labeled particles. Prog. Cardiovasc. Dis. 20:55-79.

15. Clyman, R. I., A. Jobe, M. Heymann, M. Ikegami, C. Roman, B. Payne, and F. Mauray. 1982. Increased shunt through the patent ductus arteriosus after surfactant replacement therapy. J. Pediatr. 100:101-107.

16. Baylen, B. G., H. Ogata, M. Ikegami, H. C. Jacobs, A. Jobe, and G. Emmanouilides. 1983. Left ventricular performance and regional blood flow before and after ductus arteriosus occlusion in premature lambs treated with surfactant. Circulation. 67:837-843.

17. Bligh, E. G., and W. J. Dyer. 1959. A rapid method of total lipid extraction and purification. Can. J. Biochem. Physiol. 37:911-917.

18. Jobe, A. 1977. The labeling and biological half-life of phosphatidylcholine in subcellular fractions of rabbit lung. Biochim. Biophys. Acta. 489:440-453.

19. Bartlett, G. R. 1959. Phosphorus assay in column chromatography. J. Biol. Chem. 234:466-468.

20. Robertson, B. 1980. Surfactant substitution: experimental models and clinical applications. Lung. 158:57-68.

21. Robertson, B. 1981. Neonatal pulmonary mechanics and morphology after experimental therapeutic regimens. In Reviews in Perinatal Medicine. E. M. Scarpelli and E. V. Cosini, editors. Raven Press, New York. 4:337-379. 
22. Metcalfe, I. L., R. Burgoyne, and G. Enhorning. 1982. Surfactant supplementation in the preterm rabbit: effect of applied volume on compliance and survival. Pediatr. Res. 16:834-839.

23. Bland, R. D., T. N. Hansen, C. M. Haberkern, M. A. Bressack, T. A. Hazinski, J. Usha Raj, and R. B. Goldberg. 1982. Lung fluid balance in lambs before and after birth. J. Appl. Physiol. 53:992-1004.

24. Morley, C. J., N. Miller, A. D. Banghan, and J. A. Davis. 1981. Dry artificial lung surfactant and its effect on very premature babies. Lancet. I:64-68.

25. Ikegami, M., F. H. Adams, B. Towers, and A. B. Osher. 1980. The quantity of natural surfactant necessary to prevent to respiratory distress syndrome in premature lambs. Pediatr. Res. 14:1082-1085.

26. Jobe, A., H. Jacobs, M. Ikegami, and S. Jones. 1983. Cardio- vascular effects of surfactant suspensions given by tracheal instillation to premature lambs. Pediatr. Res. 17:444-448.

27. Edmunds, L. H., W. M. Gold, and M. A. Heymann. 1970. Lobar distribution of pulmonary arterial blood flow in awake standing dogs. Am. J. Physiol. 219:1779-1783.

28. Goldsmith, J. P., and E. H. Karotkin. 1981. Assisted Ventilation of the Neonate. W. B. Saunders Co., Philadelphia. 358.

29. West, J. B., C. T. Dollery, and A. Naimark. 1964. Distribution of blood flow in isolated lung: relation to vascular and alveolar pressures. J. Appl. Physiol. 19:713-724.

30. Niden, A. H. 1964. The acute effects of atelectasis on the pulmonary circulation. J. Clin. Invest. 43:810-824. 